\title{
Forced Limb-Use Effects on the Behavioral and Neurochemical Effects of 6-Hydroxydopamine
}

\author{
Jennifer L. Tillerson, ${ }^{1}$ Ann D. Cohen, ${ }^{1}$ Jennifer Philhower, ${ }^{1,2}$ Gary W. Miller, ${ }^{1,2}$ Michael J. Zigmond, ${ }^{3}$ and \\ Timothy Schallert ${ }^{1,4}$ \\ 1/nstitute for Neuroscience and the 2Division of Pharmacology and Toxicology, University of Texas at Austin, Austin, Texas \\ 78712, ${ }^{3}$ Department of Neurology, University of Pittsburgh, Pittsburgh, Pennsylvania 15213, and ${ }^{4}$ University of Michigan, \\ Ann Arbor, Michigan 48109
}

Rats with unilateral depletion of striatal dopamine (DA) show marked preferential use of the ipsilateral forelimb. Previous studies have shown that implementation of motor therapy after stroke improves functional outcome (Taub et al., 1999). Thus, we have examined the impact of forced use of the impaired forelimb during or soon after unilateral exposure to the DA neurotoxin 6-hydroxydopamine (6-OHDA). In one group of animals, the nonimpaired forelimb was immobilized using a cast, which forced exclusive use of the impaired limb for the first $7 \mathrm{~d}$ after infusion. The animals that received a cast displayed no detectable impairment or asymmetry of limb use, could use the contralateral (impaired) forelimb independently for vertical and lateral weight shifting, and showed no contralateral turning to apomorphine. The behavioral effects were maintained through- out the $60 \mathrm{~d}$ of observation. In addition to the behavioral sparing, these animals showed remarkable sparing of striatal DA, its metabolites, and the expression of the vesicular monoamine transporter, suggesting a decrease in the extent of DA neuron degeneration. Behavioral and neurochemical sparing appeared to be complete when the $7 \mathrm{~d}$ period of immobilization was initiated immediately after 6-OHDA infusion, only partial sparing was evident when immobilization was initiated $3 \mathrm{~d}$ postoperatively, and no sparing was detected when immobilization was initiated $7 \mathrm{~d}$ after 6-OHDA treatment. These results suggest that physical therapy may be beneficial in Parkinson's disease.

Key words: motor therapy; Parkinson's disease; neurodegeneration; plasticity; movement; dopamine
Parkinson's disease is characterized by progressive motor impairment caused primarily by degeneration of nigrostriatal dopamine (DA) neurons (for review, see Olanow and Tatton, 1999). Compensating neurobiological changes and learned behavioral strategies may delay the appearance of symptoms until the loss of terminals in the striatum becomes extensive enough to overcome the capacity of the system (Morgan et al., 1983; Zigmond and Stricker, 1984; Fearnley and Lees, 1991; Lees, 1992; Zigmond, 1997; Swinnen et al., 2000). The clinical deficits can be ameliorated by pharmacotherapy; however, over time, efficacy wanes and side effects become unacceptable (Birkmayer and Riederer, 1975; Delaney and Fermaglich, 1976; Luquin et al., 1992; Lindner et al., 1999). In addition, whereas some surgical approaches are being used in the treatment of Parkinson's disease, these treatments are incomplete at best (Ghika et al., 1999). Many investigators are focusing their attention on providing exogenous trophic factors to prevent the degeneration of the DA neurons (Dunnett et al., 1988; Rosenblad et al., 1996, 1998, 1999; Choi-Lundberg et al., 1998; Lapchak, 1998; Connor et al., 1999; Mandel et al., 1999a,b; Kozlowski et al., 2000). It occurred to us, however, that if one could stimulate the capacity of the brain to generate these

\footnotetext{
Received Nov. 21, 2000; revised March 20, 2001; accepted March 21, 2001.

This work was supported by National Institutes of Health Grants NS23979 (T.S.), NS19608 (M.J.Z.) and ES09248 (G.W.M.). We thank Sandra Castro for technical assistance, Dr. Amanda Smith for helpful comments, and Dr. Pat Randall for assistance with statistical processing.

Correspondence should be addressed to Jennifer L. Tillerson, Institute for Neuroscience, 330 Mezes Hall, University of Texas, Austin, TX 78712. E-mail: tillerson@psy.utexas.edu.

Copyright (c) 2001 Society for Neuroscience 0270-6474/01/214427-09\$15.00/0
}

protective molecules, it may be possible to retard or prevent the neurodegenerative processes without the methodological problems of exogenous growth factor therapies.

One feature of Parkinson's disease is that movement is difficult and inactivity becomes more prominent. Early in the disease, patients may learn to engage in alternative behavioral strategies that lead to even greater dependence on lesscompromised motor systems, an observation typical of animal models of the disease (Schallert, 1988; Schallert and Hall, 1988; Lees, 1992; Schallert et al., 2000a; Whishaw, 2000). However, motor training has been associated with glial cell proliferation, changes in neurotransmitter levels (MacRae et al., 1987a,b; Bland et al., 1999; Humm et al., 1999), the expression of endogenous neurotrophic factors (Bortz et al., 1981; Neeper et al., 1995; Gomez-Pinilla et al., 1998), and the growth of neuronal processes (Jones and Schallert, 1994; Kleim et al., 1996; Schallert et al., 1997; Kempermann et al., 1998a,b; Coq and Xerri, 1999; Gould et al., 1999; for review, see Kolb and Whishaw, 1998; Klintsova and Greenough, 1999; Ivanco and Greenough, 2000). If the ameliorative effect that exercise has on other neurodegenerative events were to occur in Parkinson's disease, a program of motor therapy that targeted affected motor processes might retard the neurodegenerative cascade. Indeed, this may explain why physical therapy can enhance motor ability in Parkinson's disease and may even slow the degenerative process (Bilowit, 1956; Knott, 1957; Franklyn et al., 1981; Szekely et al., 1982; Freed and Yamamoto, 1985; Palmer et al., 1986; Hurwitz, 1989; Sasco et al., 1992; Toole et al., 1999; Hirsch, 2000; Schallert et al., 2000b). We have used an animal model of Parkinson's disease 
to test the hypothesis that targeted motor therapy will have a beneficial effect.

\section{MATERIALS AND METHODS}

\section{Animals}

Sixty-eight male hooded Long-Evans rats weighing between 350 and 450 $\mathrm{gm}$ at the time of lesioning were used. Fifty-seven animals were tested on behavioral analyses and used for long-term examination of DA loss. A subset of animals $(n=11)$ was examined for expression of the vesicular monoamine transporter (VMAT2). The rats were housed in groups of three in clear Plexiglas cages containing sawdust. Animals were maintained on a $12 \mathrm{hr}$ light/dark cycle and given food and water ad libitum. Animals were gently handled at least twice a week for 5 min for 1 month before surgery and behavioral testing. All procedures were approved by the Institutional Animal Care and Use Committee of the University of Texas, Austin, and were in conformity with National Institutes of Health Guidelines.

\section{Surgical procedure}

Animals were anesthetized with Equithesin $(25 \mathrm{mg} / \mathrm{kg}$ pentobarbital and $150 \mathrm{mg} / \mathrm{kg}$ chloral hydrate, $0.35 \mathrm{cc} / 100 \mathrm{gm}$, i.p.) followed by atropine sulfate $(0.1 \mathrm{mg} / \mathrm{kg}$, i.p.) to facilitate respiration before being placed in the stereotaxic apparatus. Animals also received an injection of desipramine $\mathrm{HCl}$ (DMI; $15 \mathrm{mg} / \mathrm{kg}$, i.p.), a norepinephrine reuptake inhibitor, $30 \mathrm{~min}$ before the infusion of 6-hydroxydopamine (6-OHDA), a selective neurotoxin for catecholamine neurons. In 54 animals, 6-OHDA $(10 \mu \mathrm{g} / 4 \mu \mathrm{l})$, unless otherwise noted, was infused unilaterally $(0.5 \mu \mathrm{l} / \mathrm{min})$ into the medial forebrain bundle $(3.3 \mathrm{~mm}$ posterior and $1.7 \mathrm{~mm}$ to bregma and 9 $\mathrm{mm}$ ventral to dura). Control-operated animals received all standard stereotaxic surgical procedures up to, but not including, lowering of the inf usion cannula. After surgery, all animals were placed in an incubator to minimize hypothermia.

\section{Temperature monitoring}

In a subset of animals $(n=6)$, core temperature was monitored every 15 $\min$ for the first $8 \mathrm{hr}$ after the lesion and every $8 \mathrm{hr}$ thereafter up to 36 hr.

\section{Forelimb immobilization (casting) procedures and treatment groups}

Animals were randomly assigned to one of four lesioned groups or three sham-treated groups: (1) lesioned + no cast $(n=17)$, (2) lesioned + casts on postoperative days $1-7$ ( $n=14$; early casts), (3) lesioned + casts on postoperative days 7-13 ( $n=12$; late casts), (4) lesioned + casts on postoperative days 3-9 $(n=9$; intermediate casts $)$, (5) sham + no casts $(n=5),(6)$ sham + casts on postoperative days $1-7(n=8)$, or $(7)$ sham + casts on postoperative days $7-13(n=3)$. Groups receiving casts were fitted with casts composed of plaster of Paris designed to immobilize the ipsilateral (nonimpaired) forelimb after surgery. Animals were allowed to recover to the point of moderate consciousness (determined by orientation to whisker stimulation) before casting. The average time between the completion of surgery and casting was $2 \mathrm{hr}$. The ipsilateral forelimb was placed in a naturally retracted position against the sternum, and strips of casting material were formed around the limb and upper torso (Jones and Schallert, 1994).

\section{Behavioral testing and limb-use observations}

The degree of damage to nigrostriatal DA neurons can be assessed using sensitive drug and nondrug tests (Ungerstedt, 1971; Hefti et al., 1980; Schultz, 1982; Robinson and Becker, 1983; Zigmond and Stricker, 1989; Buonamici et al., 1990; Miklyaeva et al., 1994, 1995; Miklyaeva and Whishaw, 1996; Schwarting and Huston, 1996). A battery of tests of behavioral asymmetry (Schallert and Tillerson, 1999) was performed before and after surgery. Our previous experience indicates that behavioral scores in these asymmetry tests are not influenced by repeated testing. Tests were performed before surgery and on days 14, 21 , and 28 after surgery. Limb-use asymmetry was analyzed additionally on days 40 and 60 .

Limb-use asymmetry test. Forelimb placing and use during explorative activity was analyzed by videotaping rats in a transparent cylinder $(20 \mathrm{~cm}$ diameter and $30 \mathrm{~cm}$ height) for $5 \mathrm{~min}$ (see Schallert and Tillerson, 1999; Schallert et al., 2000a). A mirror was placed behind the cylinder at an angle to permit recording of forelimb movements whenever the animal was turned away from the camera. The cylinder was high enough that the animal could not reach the top edge by rearing and wide enough to permit a $2 \mathrm{~cm}$ space between the tip of the snout and the base of the tail when the animal was not rearing. Observers were blind to the condition of the animal and used a video recorder with slow motion and frame-byframe capabilities to score the movements.

The extent of forelimb-use asymmetry displayed by the animal during exploration of the cylinder walls and for landings after a rearing movement was recorded. Wall exploration included independent use of the left or right forelimb for initial contact on the wall, use of either forelimb to initiate a weight-shifting movement, use of the left or right forelimb to regain the center of gravity while moving laterally in a vertical posture, and co-use of both the left and right forelimb for contacting the wall or lateral stepping movements along the wall. Landing included independent use of the left or right forelimb to land after a rearing movement and simultaneous use of both the left and right forelimb for landing after a rearing movement. If a rater could not clearly determine whether one limb was being used independently or simultaneously, that movement was not scored.

Wall exploration and landing scores were determined separately, and each was expressed in terms of (1) the percentage of use of the nonimpaired forelimb relative to the total number of limb-use movements, (2) the percentage of use of the impaired forelimb relative to the total number of limb-use movements, and (3) the percentage of co-use of both limbs relative to the total number of limb-use movements. The percentage of use of the impaired forelimb was then subtracted from the percentage of use of the nonimpaired forelimb for exploration and landing. These two scores (wall and landing) were averaged together for a single limb-use asymmetry score that corrected for variability in the number of wall versus landing movements (Schallert and Tillerson, 1999).

Additional details include the following. During a rearing movement, the first limb to contact the wall was scored as an independent wall placement for that limb. Placement of the other limb on the wall while maintaining the initial placement was scored as a movement involving both limbs (co-use). If instead, the animal simultaneously placed both paws on the wall, this was also scored as co-use of both limbs. For an animal to be scored as moving a second time, it was necessary that both paws first be removed from the vertical surface or that the animal explore the wall laterally alternating both limbs on the wall. The latter movement was scored as co-use of both limbs, and every additional combination of the two-limb movements (wall stepping) received an additional co-use score. After a rearing movement in which the animal has contacted the wall, the first limb to contact the ground was scored as a landing movement for that limb. Likewise, if both limbs were used simultaneously to terminate a rearing movement, the movement was scored as involving both limbs. However, movements along the ground after landing (stepping) were not included in the analysis. In addition, instances in which an animal performed $<5$ landings and $<10$ wall movements during a testing session were not included in the analysis.

Vibrissae-elicited forelimb placing. A vibrissae-elicited forelimb-placing test was used. Animals were held by their torsos, allowing forelimbs to hang free. Independent testing of each forelimb was induced by gently brushing the respective vibrissae on the edge of a tabletop once per trial for 10 trials. Intact animals place the forelimb of both sides quickly onto the countertop. Rats with unilateral 6-OHDA treatment show varying degrees of impaired limb-placing ability, while still placing the unimpaired limb reliably. The percentages of unsuccessful placing responses were determined [(the number placed contralaterally divided by the number placed ipsilaterally) $\times 10]$.

Test for forelimb akinesia. Movement initiation for each limb was assessed using the forelimb akinesia test (described previously in Schallert et al., 1992; Olsson et al., 1995; Lindner et al., 1997; Schallert and Tillerson, 1999). The hindquarters of the animals were suspended while the animal supported its weight on only one forelimb (Fig. 1). The animal was allowed to initiate stepping movements in a $10 \mathrm{sec}$ period for one forelimb and then the other in a balanced order. Stepping measures for both limbs were recorded, and an ipsilateral asymmetry score was derived [(ipsilateral steps/ipsilateral plus contralateral steps) - (contralateral steps/ipsilateral plus contralateral steps)].

Apomorphine rotation. On day 21 after 6-OHDA infusion, the animals received an injection of the DA receptor agonist apomorphine (0.5 $\mathrm{mg} / \mathrm{kg}$, s.c.). Rats were then placed in a plastic bowl, and the number of rotations in a $90 \mathrm{~min}$ trial was recorded (Ungerstedt, 1971). 


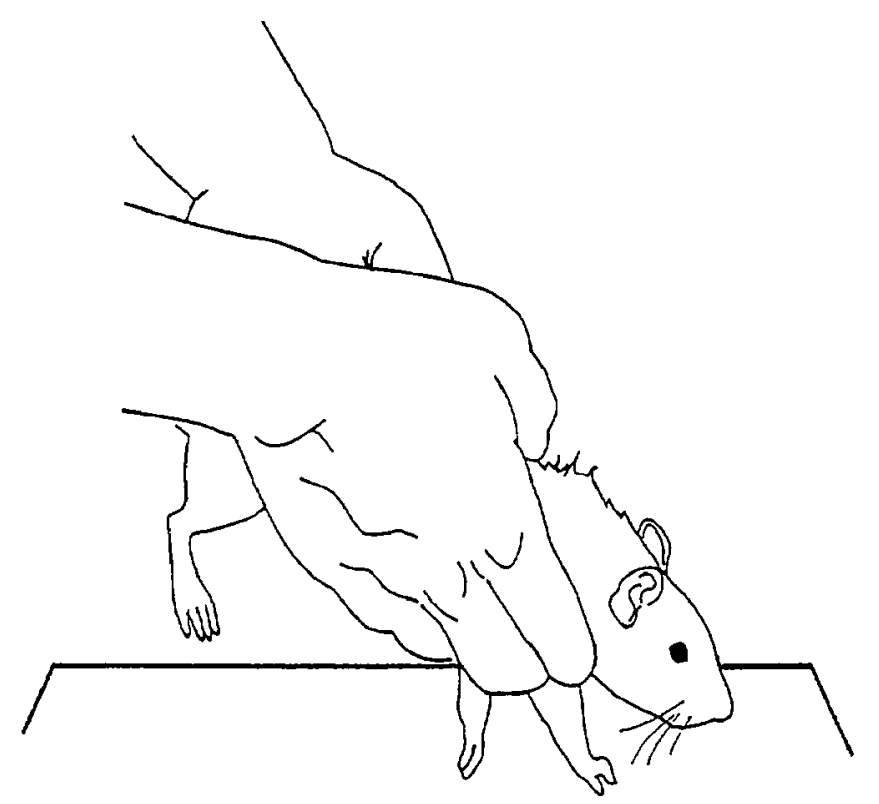

Figure 1. Example of the appropriate positioning of a rat during the test for forelimb akinesia. The hindquarters of an animal are suspended while the animal supports its weight on only one forelimb. The animal is allowed to initiate stepping movements in a $10 \mathrm{sec}$ period for one forelimb and then the other in a balanced order.

\section{Neurochemical analyses}

Analysis of $D A$ and metabolites. Animals were anesthetized and killed 65-80 d after receiving the lesion $(n=57)$. Their brains were removed, and a $1 \mathrm{~mm}$ section of the striatum (1 $\mathrm{mm}$ anterior to bregma) was dissected for both the ipsilateral and contralateral hemispheres. Tissue samples were homogenized in $0.1 \mathrm{~mm}$ perchloric acid containing $0.2 \mathrm{~mm}$ sodium bisulfate. The homogenates were centrif uged for $10 \mathrm{~min}$, and the supernatant was removed and stored at $-80^{\circ} \mathrm{C}$ until assayed for DA, dihydroxyphenylacetic acid (DOPAC), and homovanillic acid (HVA). Supernatant $(20 \mu \mathrm{l})$ was injected onto a Symmetry $\mathrm{C}_{18}$ column $(3 \mathrm{~mm}$ particle size; $3.9 \times 150 \mathrm{~mm}$; Waters Associates, Milford, MA). The mobile phase consisted of $50 \mathrm{mM} \mathrm{H}_{2} \mathrm{NaPO}_{4}, 0.72 \mathrm{~mm}$ sodium octyl sulfate, $0.075 \mathrm{~mm} \mathrm{Na}{ }_{2}$ EDTA, and $16 \%$ methanol (v/v), $\mathrm{pH}$ 2.7. The mobile phase was pumped through the system at $1.2 \mathrm{ml} / \mathrm{min}$ using a Shimadzu LC-10AD pump (Shimadzu Scientific Instruments, Inc., Columbia, MD). Compounds were detected and quantified with an ESA coulochem detector (model 5100A) equipped with conditioning (model 5010 ) and microdialysis cells (model 5014B; E1 $=+0.26 \mathrm{~V}, \mathrm{E} 2=+0.28$ $\mathrm{V}$, and guard cell $=+0.4 \mathrm{~V}$; ESA, Inc.). Samples were expressed as nanograms per $20 \mathrm{gm}$ of wet weight. The limits of detection for DA, DOPAC, and HVA were $2 \mathrm{pg} / 20 \mu \mathrm{l}$. Water was purified by reverse osmosis (Millipore, Bedford, MA) before use. All reagents were of the highest available purity and were purchased from Fisher Scientific (Houston, TX) unless otherwise noted.

Quantification of VMAT2. Animals were anesthetized with carbon dioxide and decapitated $21 \mathrm{~d}$ after receiving the lesion $(n=11)$. A $1 \mathrm{~mm}$ section of the striatum ( $+1 \mathrm{~mm}$ to bregma) was dissected for both the ipsilateral and contralateral hemispheres. Samples were homogenized in buffer (320 mM sucrose and $5 \mathrm{mM}$ HEPES). Homogenized samples were centrifuged at $2000 \times g$ for $5 \mathrm{~min}$, and the resulting supernatant was recentrifuged at $30,000 \times g$ for $30 \mathrm{~min}$. The final pellet was resuspended in homogenization buffer and subjected to SDS-PAGE (Novex; 10\% SDS-PAGE). Samples were electrophoretically transferred to a polyvinylidene difluoride membrane, and nonspecific sites were blocked in 5\% nonfat dry milk in Tris-buffered saline $(135 \mathrm{~mm} \mathrm{NaCl}, 2.5 \mathrm{~mm} \mathrm{KCl}, 50$ mM Tris, and $0.1 \%$ Tween $20, \mathrm{pH} 7.4$ ). The samples were then incubated in a polyclonal antibody to the C terminal of VMAT2 (pAB VMAT2-Ct; Chemicon, Temecula, CA) in Tris-buffered saline with $2 \%$ nonfat dry milk. VMAT2 antibody binding was detected using a goat anti-rabbit horseradish peroxidase secondary antibody (Bio-Rad, Hercules, CA) and

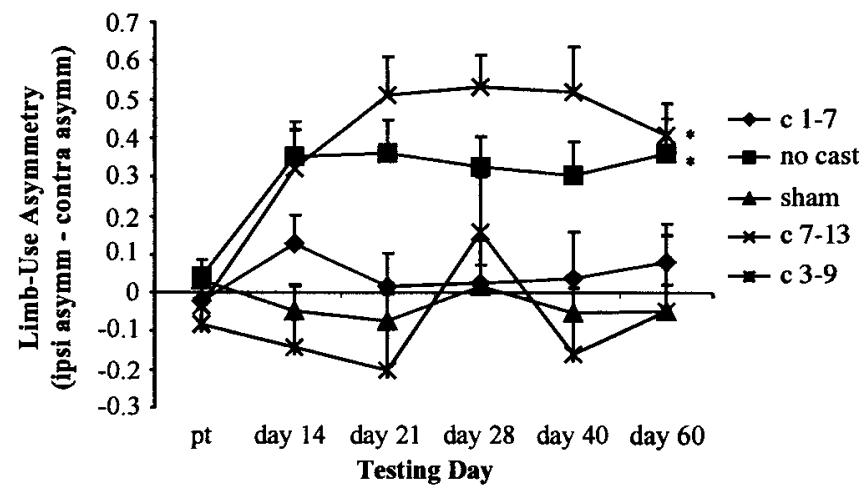

Figure 2. Limb-use asymmetry was prevented with early forced use, but not in animals in a delayed forced-use condition, which showed behavior similar to that of noncast animals. Animals that received the cast on days 3-9 also showed no significant group difference from shams. Bonferroni post hoc analysis indicated significant differences $(*)$ between sham controls (sham) and lesion + no cast (no cast) and lesion + late cast (c 7-13) groups.

enhanced chemiluminescence (Pierce, Rockford, IL). Chemiluminesent signal was captured on an $\alpha$ Innotech Chemi-Imager and stored as a digital image. Densitometric analysis was performed and calibrated to coblotted dilutional standards of control striatum. Blots were then stripped for $20 \mathrm{~min}$ at $80^{\circ} \mathrm{C}(8 \mathrm{M}$ urea, $100 \mathrm{~mm}$ 2-mercaptoethanol, and 62.5 mm Tris, pH 6.8) and reprobed with $\alpha$-tubulin (Sigma, St. Louis, MO).

\section{Statistical analyses}

DA, VMAT2, and apomorphine rotation were analyzed by applying a one-way ANOVA for group using SPSS Software. Temperature was analyzed with an overall, repeated measures ANOVA. Behavioral observations were first subjected to a traditional overall, repeated measures ANOVA. For cases in which the group-by-day interaction was significant, two-factor ANOVAs for each experimental group versus control were run as post hoc tests to determine the source of the interaction. This procedure is analogous to Dunnet's test for all groups versus control; the tests were Bonferroni corrected to keep the overall error rate per group of two-way interactions at 0.05 . Because no statistical differences were seen among the three sham control groups, these data have been combined into a single control group.

\section{RESULTS}

\section{Long-term behavioral effects of forelimb immobilization in animals with unilateral depletion of the nigrostriatal pathway}

\section{Limb-use asymmetry test}

Casting the nonimpaired forelimb during the first week after surgery, but not during days 7-13, prevented the preferential use of the nonimpaired forelimb for vertical exploration (Fig. 2). Immobilization of the nonimpaired forelimb in sham animals did not result in a significant behavioral difference between sham + early cast, sham + late cast, and sham + no cast groups $\left(F_{(2,12)}=\right.$ $1.89 ; p>0.05)$. Therefore, these three groups were pooled. Two-way ANOVA revealed a main effect for treatment group $\left(F_{(4,60)}=9.29 ; p<0.05\right)$ and a significant group-by-day interaction $\left(F_{(20,300)}=2.84 ; p<0.05\right)$. Post hoc analysis compared each lesion group with the pooled sham group. Animals that received a cast immediately after surgery through day 7 (early cast) were not different from intact animals in the limb-use asymmetry task [group $\left(F_{(1,26)}=0.79\right)$; group-by-day interaction $\left(F_{(5,130)}=\right.$ $0.77)]$. Similar to the animals that received a cast immediately after surgery, animals that were cast on days 3-9 (intermediate) did not show a significant group difference when compared with sham animals $\left(F_{(1,20)}=0.48\right)$, and there was no significant inter- 


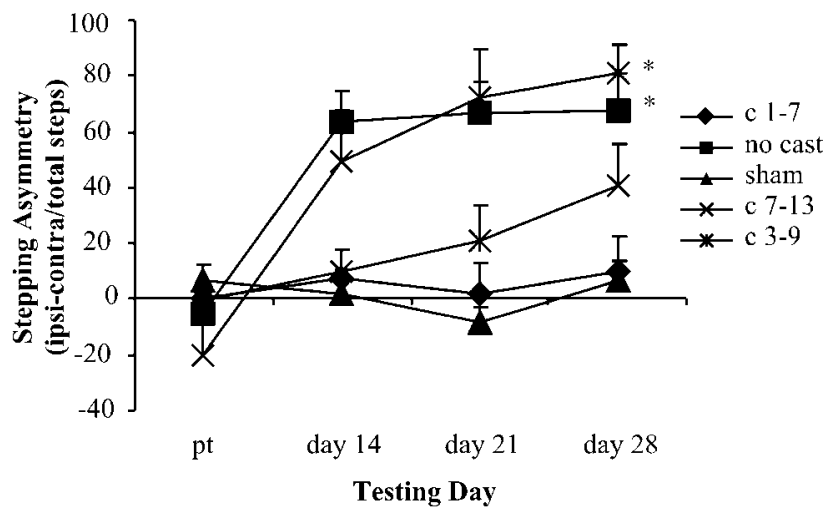

Figure 3. Forced use of the impaired forelimb on days 1-7 and 3-9 after 6-OHDA exposure ameliorated akinesia. Those animals that did not receive the cast until days 7-13 displayed strong akinetic tendencies as did the animals in the no cast group. Bonferroni post hoc analysis indicated significant differences $(*)$ between sham controls and lesion + no cast and lesion + late cast groups.

action $\left(F_{(5,100)}=0.84\right)$. Animals that did not receive a cast showed a significant group effect $\left(F_{(1,30)}=15.70 ; p<0.05\right)$ when compared with shams as well as a significant interaction $\left(F_{(5,150)}\right.$ $=4.79 ; p<0.05)$. Thus, in uncast animals, 6-OHDA caused a reliable and chronic asymmetry of spontaneous forelimb use after surgery. Limb-use asymmetry in animals that were delay-cast (cast during days 7-13) was significantly different from that of sham animals $\left(F_{(1,23)}=32.7 ; p<0.05\right)$, and there was a significant interaction $\left(F_{(5,115)}=8.52 ; p<0.05\right)$. Thus, forced use of the impaired forelimb during the first $7 \mathrm{~d}$ after 6-OHDA exposure, but not delayed forced use, prevented limb-use asymmetry.

In addition, the number of rears, as a measure of overall activity, was analyzed. A significant group-by-day interaction $\left(F_{(20,315)}=2.26 ; p<0.05\right)$ was found. For post hoc analysis, the pretest data were excluded to control for the decrease in rears after surgery, and an overall group effect was found $\left(F_{(4,63)}=\right.$ $3.15 ; p<0.05)$. Further post hoc analysis revealed that only the animals cast on days 3-9 (intermediate) significantly differed from shams in the number of rears after surgery, and this significance was lost after error correction. Thus, there was no significant difference among the groups in the number of rears after surgery.

\section{Test for forelimb akinesia}

Casting the nonimpaired forelimb during the first week after 6-OHDA prevented akinesia, whereas delayed casting on days 7-13 did not result in decreased akinesia (Fig. 3). There were no significant differences among the three sham groups on akinetic scores, and these three groups were pooled for further analysis $\left(F_{(2,13)}=0.61\right)$. An overall two-way ANOVA revealed a main effect for treatment group $\left(F_{(4,54)}=9.44 ; p<0.05\right)$ and for day $\left(F_{(3,162)}=25.11 ; p<0.05\right)$ and a significant group-by-day interaction $\left(F_{(12,162)}=7.33 ; p<0.05\right)$. As in the limb-use asymmetry analysis, primary interest lay in comparing each group with the pooled sham group. Post hoc analyses again revealed that cast treatment on days 1-7 (early) and cast treatment on days 3-9 (intermediate) ameliorated akinesia and hypokinesia after 6-OHDA. Thus, no significant group effect $\left(F_{(1,26)}=0.00\right)$, day effect $\left(F_{(3,78)}=1.14\right)$, or interaction $\left(F_{(3,78)}=0.7\right)$ was found between the lesion + early cast group and the sham group or between the lesion + intermediate cast group and the pooled sham group [group $\left(F_{(1,22)}=3.72\right)$; day $\left(F_{(3,66)}=3.34\right)$; interaction $\left.\left(F_{(3,66)}=3.84\right)\right]$. In contrast, when compared with shams,

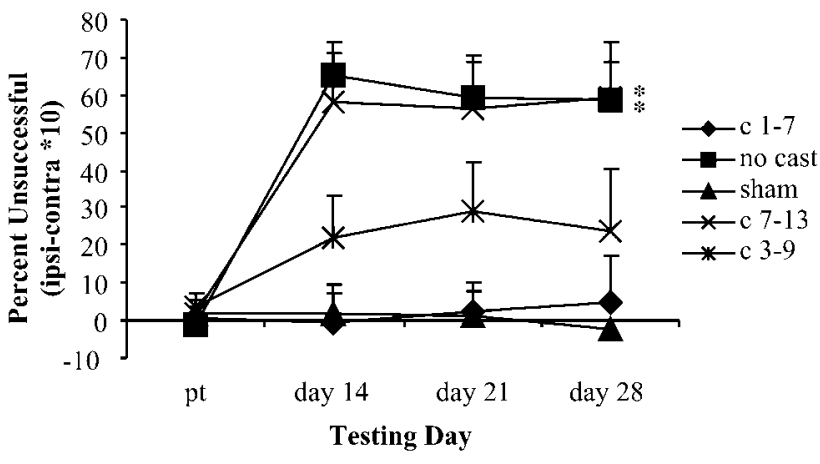

Figure 4. Limb-placing deficits were prevented by early (days 1-7) and intermediate (days 3-9) forced use of the impaired forelimb. The no treatment and late (days 7-13) treatment groups were significantly different $(*)$ from the sham groups with an increased limb-placing deficit.

animals that did not receive a cast showed a significant group effect $\left(F_{(1,30)}=25.91 ; p<0.05\right)$, a significant day effect $\left(F_{(3,90)}=\right.$ 9.78; $p<0.05)$, and a significant interaction $\left(F_{(3,90)}=13.78 ; p<\right.$ $0.05)$. Like the noncast group, animals that were not given a cast until days 7-13 (late) showed increased akinesia relative to sham animals [group $\left(F_{(1,21)}=16.43 ; p<0.05\right)$; day $\left(F_{(3,63)}=15.65\right.$; $p<0.05)$; interaction $\left.\left(F_{(3,63)}=19.70 ; p<0.05\right)\right]$. Therefore, early, but not late, forced use of the impaired forelimb significantly reduced akinesia.

\section{Forelimb placing}

Casting the nonimpaired forelimb during the first week after the lesion, but not during the second week, prevented placing deficits (Fig. 4). As with the other analyses, sham groups were pooled because statistical analysis indicated that they did not differ. An overall two-way ANOVA revealed a main effect for treatment $\operatorname{group}\left(F_{(4,61)}=11.19 ; p<0.05\right)$ and for day $\left(F_{(3,183)}=20.90 ; p<\right.$ $0.05)$ and a significant group-by-day interaction $\left(F_{(12,183)}=6.11\right.$; $p<0.05)$. Post hoc analyses showed animals in casts on days 1-7 (early) or on days 3-9 (intermediate) were not significantly impaired in placing ability when compared with sham animals. That is, no significant group effect $\left(F_{(1,28)}=0.03\right)$, day effect $\left(F_{(3,84)}=\right.$ $0.01)$, or interaction $\left(F_{(3,84)}=0.34\right)$ was found between the lesion + early cast group and the sham groups or between the lesion + intermediate cast group and the sham groups [group $\left(F_{(1,22)}=\right.$ $2.95)$; day $\left(F_{(3,66)}=1.64\right)$; interaction $\left.\left(F_{(3,66)}=2.27\right)\right]$. In contrast, animals that did not receive a cast showed a significant group effect $\left(F_{(1,31)}=30.68 ; p<0.05\right)$ when compared with shams and significant day $\left(F_{(3,93)}=18.54 ; p<0.05\right)$ and significant interaction $\left(F_{(3,93)}=20.29 ; p<0.05\right)$ effects. Mirroring the noncast group, animals that were not given a cast until days 7-13 (late) were significantly different when compared with sham animals [group $\left(F_{(1,25)}=19.47 ; p<0.05\right)$; day $\left(F_{(3,75)}=9.34 ; p<\right.$ $0.05)$; interaction $\left.\left(F_{(3,75)}=10.59 ; p<0.05\right)\right]$. Again, early forced use of the impaired forelimb, but not late forced use, prevented limb-placing deficits.

\section{Apomorphine rotation}

Casting of the nonimpaired forelimb for the first $7 \mathrm{~d}$ after 6-OHDA reduced contralateral turning to apomorphine, this reduction was not seen if casting was delayed until the second week (Fig. 5). The number of turns per trial was not significantly different among any of the sham groups, and these three groups were combined. A one-way ANOVA revealed significant differences between groups $\left(F_{(4,50)}=6.549 ; p<0.05\right)$ for the extent of 


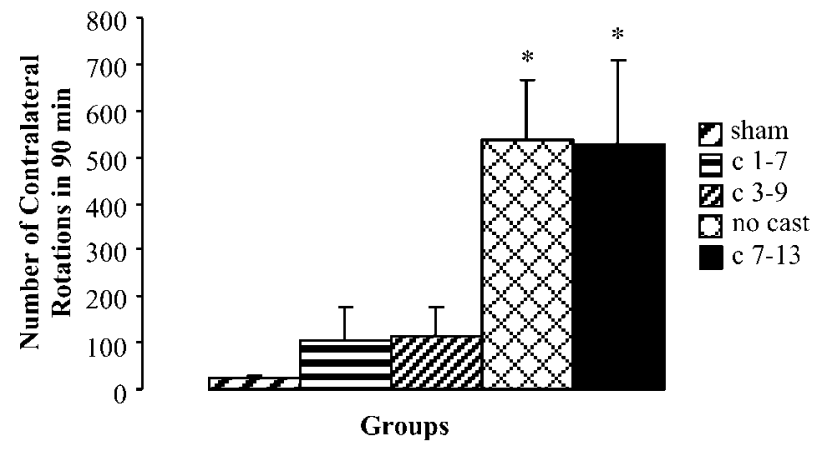

Figure 5. The number of contralateral rotations for sham groups was significantly different $(*)$ from that of both the lesioned + no cast group and the lesioned + late cast group. Animals that received casts on days 1-7 or 3-9 did not differ from sham animals. Contralateral rotations were determined by counting the number of contralateral rotations in a $90 \mathrm{~min}$ period after apomorphine administration.

apomorphine-induced rotation. Post hoc analysis revealed a significant difference between lesion + no cast and sham groups $\left(F_{(1,31)}=13.849 ; p<0.05\right)$ and between lesion + late cast and sham groups $\left(F_{(1,18)}=35.172 ; p<0.05\right)$ but no significant difference in the number of turns displayed by the lesion + early cast group and the sham group $\left(F_{(1,26)}=1.626\right)$ or the lesion + intermediate cast group $\left(F_{(1,20)}=3.165\right)$.

\section{Neurochemistry}

Percentage of $D A$ remaining in the lesioned striatum

The percentage of DA, DOPAC, and HVA remaining in the lesioned hemisphere was calculated by dividing the amount of each compound in the striatum of the lesioned hemisphere by the content of the striatum in the nonlesioned hemisphere. No significant difference was found in the content of nonlesioned animal groups for any of these measures; therefore these groups were combined for further analysis. In addition, mean levels of DA, DOPAC, and HVA in the nonlesioned striatum were not significantly different between groups. Thus, ratio scores are an accurate representation of the depleted hemisphere, and no compensatory or use-related increases or decreases in the nonlesioned hemispheres were apparent $60 \mathrm{~d}$ after the lesion. DA levels in the lesioned striatum were as follows (expressed as nanograms per 20 gm of wet weight): sham, $8800 \pm 540$; early cast, $6600 \pm 520$; intermediate cast, $4500 \pm 960$; late cast, $1300 \pm 600$; and no cast, $2400 \pm 880$. DA levels in the nonlesioned striatum were as follows (expressed as nonograms per 20 gm of wet weight): sham, $8400 \pm$ 1100; early cast, $8200 \pm 690$; intermediate cast, $7200 \pm 1700$; late cast, $6400 \pm 1400$; and no cast, $8400 \pm 670$.

Neurochemical analysis revealed a protective effect of early or intermediate casting on striatal DA levels and DA metabolites (Fig. 6). A one-way ANOVA indicated a significant group effect for DA content and its metabolites [DA $\left(F_{(4,52)}=10.279 ; p<\right.$ $0.05)$; DOPAC $\left(F_{(4,46)}=10.9 ; p<0.05\right) ; \operatorname{HVA}\left(F_{(4,46)}=9.229\right.$; $p<0.05)$ ]. Post hoc analysis revealed that compared with shams, DA, DOPAC, and HVA were all significantly reduced by 6 -OHDA in the lesion + no cast group $\left[\mathrm{DA}\left(F_{(1,25)}=26.34 ; p<\right.\right.$ $0.05)$; DOPAC $\left(F_{(1,25)}=35.66 ; p<0.05\right) ; \operatorname{HVA}\left(F_{(1,25)}=28.494\right.$; $p<0.05)$ ] and in the lesion + late cast (days 7-13) group [DA $\left(F_{(1,18)}=22.87 ; p<0.05\right)$; DOPAC $\left(F_{(1,14)}=33.925 ; p<0.05\right)$; $\left.\operatorname{HVA}\left(F_{(1,14)}=15.863 ; p<0.05\right)\right]$. However, DA, DOPAC, and HVA were not significantly reduced in the lesioned striatum in the lesioned + early cast (days $1-7)$ group $\left[\mathrm{DA}\left(F_{(1,21)}=2.56\right)\right.$;

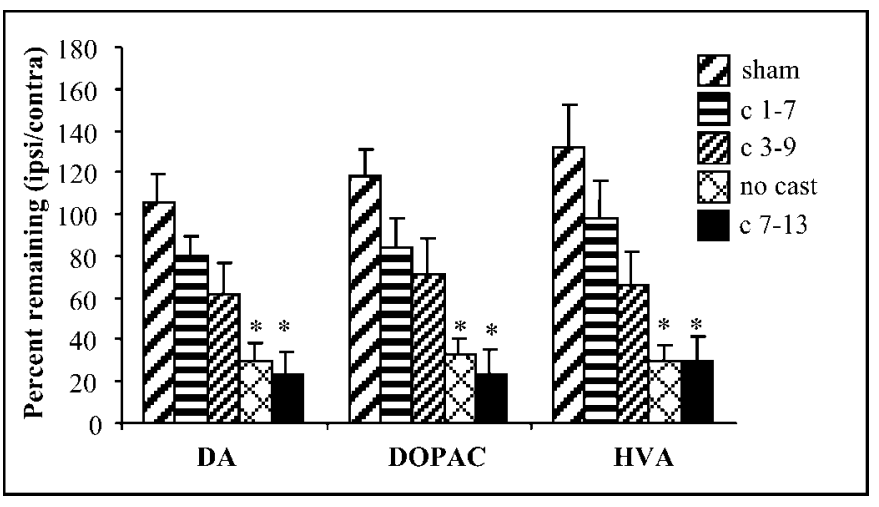

Figure 6. Animals receiving early casts (days 1-7) and sham animals do not show significant differences in DA, DOPAC, or HVA levels. Animals receiving casts on days 3-9 show intermediate DA levels, although still not significantly different from sham. Animals with late casts (days 7-13) and animals not receiving casts show significantly lower (*) DA levels when compared with sham-treated animals.

$\operatorname{DOPAC}\left(F_{(1,21)}=3.263\right)$; HVA $\left.\left(F_{(1,21)}=1.511\right)\right]$ or in the lesion + intermediate cast (days 3-9) group [DA $\left(F_{(1,15)}=4.488\right)$; $\left.\operatorname{DOPAC}\left(F_{(1,13)}=8.055\right) ; \operatorname{HVA}\left(F_{(1,13)}=6.621\right)\right]$. Thus, the impact of unilateral 6-OHDA on striatal DA, DOPAC, and HVA content appeared to be counteracted by forced reliance on the impaired limb for $7 \mathrm{~d}$ immediately after injury, but not when the intervention was delayed 1 week. As with the behavioral analyses, animals that were given a cast on days 3-9 after the lesion (intermediate) were not significantly different from shams but displayed an intermediate level of striatal DA content.

A comparison of DOPAC/DA ratios was examined between groups (using the ratios of lesioned/nonlesioned hemispheres described above). DOPAC/DA ratios often appear to reflect DA turnover. A significant group effect was found when comparing DOPAC/DA ratios $\left(F_{(4,52)}=2.258 ; p<0.05\right)$. Both sham animals and those animals cast immediately after surgery (days 1-7) showed a mean turnover of approximately one, and thus no significant effect was found between these two groups $\left(F_{(21,1)}=\right.$ $0.694)$. On the other hand, animals that did not receive a cast, along with animals that were cast on days $7-13$, showed ratios of

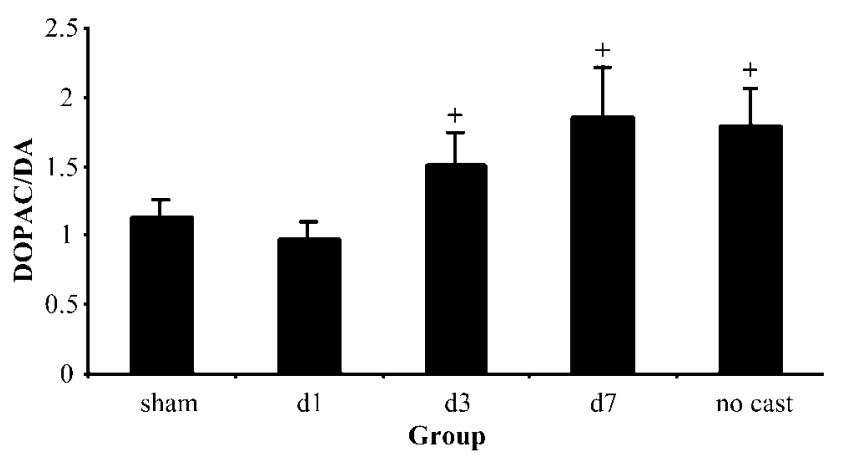

Figure 7. DOPAC/DA ratio is seen as a measure of DA turnover. The ratio is increased in lesioned plus no cast animals and in lesioned plus cast on days 3-9 (d3) and lesioned plus cast on days 7-13 (d7) groups, possibly reflecting a compensatory change in these animals. Animals that received a cast on days 1-7 (d1) do not show an increase in the DOPAC/DA ratio when compared with shams. Bonferroni post hoc analysis indicated significant trends $(+)$ between sham controls and no cast animals, as well as between sham and lesion plus late cast animals. In addition, there was a trend toward significance $(+)$ when comparing lesion plus intermediate (days 3-9) and sham animals. 
Lesion No Cast Lesion Cast D1-7 Sham

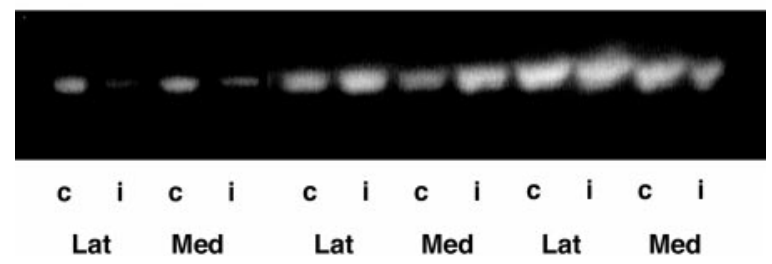

Figure 8. Vesicular monoamine transporter expression in the striatum was measured using Western blot techniques. An overall analysis of group revealed a significant difference in the amount of VMAT2 remaining in the striatum after lesioning between those animals that did not receive a cast (Lesion No Cast) and those animals that were cast for $7 \mathrm{~d}$ immediately after surgery (Lesion Cast D1-7). Each striatum was divided into lateral (Lat) and medial (Med) sections. Shown are the ipsilateral or lesioned side $(i)$ versus the contralateral or control side $(c)$. No significant differences in VMAT expression or depletion were seen between these two sections, and the data were pooled for densitometric analysis. This is a representative blot of four separate experiments.

1.8 and 1.85 , respectively. Both of these groups showed a trend toward statistical significance in post hoc comparisons with sham animals [no cast $\left(F_{(1,25)}=3.875 ; p=0.06\right)$; cast on days $7-13$ $\left.\left(F_{(1,18)}=2.8 ; p=0.1\right)\right]$. Finally, animals cast on days 3-9 showed an intermediate ratio of 1.5 . Again, there is a trend toward significance when comparing animals with intermediate casts with sham animals $\left(F_{(1,15)}=2.747 ; p=0.1\right.$; Fig. 7).

\section{Vesicular monoamine transporter expression in the} lesioned striatum

VMAT2 expression in the striatum for sham, lesion + no cast, and lesion + early cast (days 1-7) groups was analyzed $21 \mathrm{~d}$ after 6-OHDA infusion. The VMAT2 remaining in the striatum after treatment was measured as a percentage of that in the contralateral striatum (mean sham, 94.8\%; no cast, 35.4\%; early cast, $78.4 \%$ ). An overall analysis of group revealed a significant difference between lesion + no cast animals and animals cast for $7 \mathrm{~d}$ immediately after insult in the amount of VMAT2 remaining in the striatum $\left(F_{(1,8)}=7.227 ; p<0.05\right.$; Figure 8).

\section{Impact of casting on core temperature}

Temperature can play a vital part in neuroprotection (Schallert et al., 1978; Kuluz et al., 1993; Callahan and Ricaurte, 2000; Colbourne et al., 2000). Although previous work has shown that there is no detectable difference in cast versus uncast animals after stroke (Bland et al., 2000), animals in this study were pretreated with DMI, which has been found to lower body temperature in 6-OHDA-treated animals (Schallert and Wilcox, 1985). To control for this variable, body temperature was monitored in cast and noncast lesioned animals. Animals cast after surgery did not show a significant decrease in body temperature compared with lesion + no cast animals $\left(F_{(12,48)}=1.10 ; p>0.05\right)$. However, regional brain temperature differences cannot be excluded.

\section{Impact of casting of the impaired limb on behavioral and neurochemical deficits}

To control for the possibility that casting alone was the major factor in the behavioral and neurochemical sparing seen in this study, casting of the impaired (contralateral) forelimb in mildly depleted animals was explored. In this study, $5 \mu \mathrm{g}$ of 6-OHDA was infused into the medial forebrain bundle, and the impaired forelimb was cast for $7 \mathrm{~d}$ immediately after surgery. Casting the impaired forelimb forced the mildly depleted animals to rely exclusively on their unimpaired limb in a manner similar to that of severely depleted animals. Behavioral analysis in the limb-use asymmetry test was assessed at day 14 after the lesion, and DA levels were examined at $40 \mathrm{~d}$ after the lesion. Overall group analysis comparing sham, no cast, and contralateral cast on days $1-7$ revealed a group effect of behavior $\left(F_{(2,10)}=4.557 ; p<0.05\right)$ and a decrease in the percentage of DA remaining $\left(F_{(2,10)}=\right.$ 6.177; $p<0.05)$. Post hoc analysis comparing contralateral cast animals and no cast animals displays a significant trend in behavior $\left(F_{(1,7)}=3.982 ; p=0.08\right)$ and DA levels $\left(F_{(1,7)}=4.585 ; p=\right.$ $0.07)$. These findings indicate that casting alone does not cause a sparing in behavioral and neurochemical markers. In fact, casting of the impaired limb in mildly depleted animals resulted in an increase in behavioral deficits and DA loss when compared with noncast animals. These data are consistent with the view that degenerative events associated with 6-OHDA are use dependent.

\section{DISCUSSION}

After moderate 6-OHDA-induced lesions, nigrostriatal DA signaling may be maintained by reduced DA reuptake, increased DA synthesis and release, and proliferation of DA receptors (Neve et al., 1982; Zigmond and Stricker, 1984; Robinson and Whishaw, 1988; Zigmond, 1997). These changes are among those that presumably mediate the preclinical stage in neurodegenerative diseases such as Parkinson's disease. Eventually, the extent of the degeneration is too great, the compensations are inadequate, and therapy becomes necessary. Unfortunately, current therapies are incomplete, and the majority focus entirely on providing temporary symptomatic relief. In this study, we explored the hypothesis that intensive motor therapy will actually reduce or even reverse the neurodegenerative process. By immobilizing their nonimpaired forelimb with a cast, animals were forced to rely exclusively on their impaired limb for $7 \mathrm{~d}$ after unilateral infusion of 6-OHDA into the nigrostriatal pathway. These animals were comparable with sham-operated animals in behavioral and neurochemical analyses. To determine whether there might be a sensitive window of opportunity for this constraint-induced recovery, the period of forced use was delayed in two other groups. Forcing reliance on the contralateral forelimb for $7 \mathrm{~d}$ beginning on the third day after 6-OHDA resulted in some sparing of behavioral asymmetries and a partial reduction in the loss of striatal DA content. When the onset of forced motor behavior was delayed for a week, however, there was no amelioration of the behavioral deficit and no protection against the loss of striatal DA.

Among the groups, the degree of DA depletion was correlated with forelimb asymmetry $(r=0.75)$. Moreover, casting did not simply delay the loss of DA content in the early cast animals because the neurochemical assays were performed 2-3 months after the removal of the casts. A previous examination of striatal DA using Western blot analysis of VMAT2, the transport protein responsible for sequestering DA in its vesicles, was consistent with the DA content assays. VMAT2 has been found to be a highly reliable marker of the integrity of DA terminals (Kilbourn et al., 1993, 1996; Miller et al., 1999a,b). We also examined the DOPAC/DA ratio. Increases in this ratio are believed to reflect increased turnover, revealing the integrity and workload of the system. The similarities in ratios for intact and early cast animals suggest that DA turnover in these two groups was essentially the same. On the other hand, the increased ratio for noncast and late cast animals may reflect the increased DA synthesis and release of the remaining neurons in the system. Finally, those animals cast on days 3-9, which were intermediate in other measures, ap- 
peared to have a less-compromised system than did the animals that received no cast or were cast during days $7-13$ but still reflect some compensatory upregulation of DA turnover.

We believe that the present study is the first to show usedependent amelioration of the loss of a specific transmitter. There are many possible mechanisms of action that, alone or in collaboration, may explain the effect of forced use on DA neuron degeneration (for review, see Schallert et al., 2000c). The morphological changes seen after brain injury are very similar to those seen during learning and create an environment sensitive to reorganization and regeneration (Invanco and Greenough, 2000). Canals et al. (2001) have shown that striatal damage causes upregulation of endogenous BDNF in corticostriatal neurons, possibly reflecting a protective mechanism. Gould and Tanapat (1997) found that death of cells in the dentate gyrus of the adult rat leads to proliferation of precursor cells, many of which differentiated into mature granule neurons. In addition, evidence from previous research suggests that direct exercise and motor training alone can cause upregulation of trophic factor expression (Kempermann et al., 1998a,b; Gould et al., 1999a,b; van Praag et al., 1999; Gage, 2000). Thus, it is possible to upregulate growth factors after injury and via environmental manipulation. We strongly believe that increases in growth factors such as glial cell line-derived neurotrophic factor (GDNF), FGF-2, or BDNF could play a vital role in the phenomenon seen in this experiment.

The value of forced limb use has been observed in several other experimental models. For example, after injury of the sensorimotor cortex, forelimb use in the presence of axonal degeneration can enhance neuronal growth in the homotopic cortex, and disuse can prevent growth (Jones and Schallert, 1994; Bury et al., 2000). In addition, if neuronal insult is combined with behavioral experience, increases in glial fibrillary acidic protein (GFAP) and FGF-2 are seen. Increases in GFAP are seen after motor training alone, but when combined with the degeneration, the increases are even greater. Acrobatic training further enhances neural growth and synaptogenesis during axon terminal degeneration (Bury et al., 2000). Thus, it has been shown that behavioral manipulations after injury create an environment conducive to increased growth factor expression and neuronal plasticity. Indeed, preliminary results show that casting before surgery causes increased behavioral abilities in 6-OHDA-lesioned animals (our unpublished observations). We are currently exploring the possible increases in GDNF, basic FGF, and BDNF in animals after forced use of the impaired limb.

Increased use of the impaired forelimb after injury may result in many other changes that could contribute to the behavioral and neurochemical sparing. For example, there may be changes in neurotransmitter levels and/or receptor density, increases in extracellular DA and/or monoamine oxidase (MAO) activity, or changes in VMAT2 levels. Neurotransmitter and receptor changes have been implicated in behavioral and neurochemical recovery after a partial 6-OHDA lesion. Blocking glutamate activity for the first week after insult results in increased behavioral asymmetry and decreased extracellular DA (Emmi et al., 1996). Blockade of D1/D5 receptors in the same paradigm resulted in decreased behavioral sparing and decreased DA recovery (Emmi et al., 1997). In addition, glutamate was found to play a crucial role in our previous work showing exaggeration of cortical injury caused by forced use. This exaggeration is reversed by NMDA receptor antagonists (Humm et al., 1999). Moreover, vertical exploration in the cylinder is associated with increases in striatal glutamate and other neuroactive amino acids (Bland et al., 1999), and casting one limb in intact animals causes a chronic decrease in glutamate in the hemisphere corresponding to the disused forelimb (Humm et al., 1999). Therefore, changes in neurotransmitter levels in the current paradigm need to be explored.

Specific changes in DA levels or MAO concentrations could also be important. Increased extracellular DA would act to compete with 6-OHDA for uptake via the high-affinity DA transporter, thereby reducing the effects of 6-OHDA. Likewise, increases in MAO activity after forced use would lead to faster breakdown of 6-OHDA in cast animals (Schallert and Wilcox, 1985). However, we believe these to be unlikely mediators in the effect of forced use. 6-OHDA is very rapidly oxidized, and therefore, the effects of forced use are unlikely to occur by reducing the access of the neurotoxin to DA terminals, because the animals remain anesthetized for several hours after infusion and are not separated into different groups until $2 \mathrm{hr}$ after surgery. In addition, Jensen et al. (1995) found no change in MAO-B activity after exercise.

Finally, it is conceivable that increased use could alter VMAT2 function or expression. VMAT2 is known to sequester dopaminergic toxins like MPP+ and dopamine metabolites (Miller et al., 1999b). If VMAT2 can also sequester 6-OHDA, it may be possible to attenuate oxidative damage. Lack of physical activity may prevent normal VMAT2 activity, leading to an inability to maintain sequestration of toxic DA metabolites. These possibilities are speculative; indeed there is no evidence that exercise alone can alter the expression or function of VMAT2.

The effects of forced use that we have observed might be surprising because previous experiments show that forced use of the impaired forelimb causes adverse effects in rats with focal cortical lesions or ischemic injury confined to the sensorimotor cortex (Kozlowski et al., 1996; Humm et al., 1998; Kozlowski and Schallert, 1998; Risedal et al., 1999; Bland et al., 2000). However, there are several variables that differ between our previous findings and our current results, such as the rate of the injury and primary and secondary degenerative events, as well as the location of the injury.

Moreover, there are precedents for analogous effects of physical therapy. For example, Taub and associates have shown that constraint therapy, forcing use of the more affected limb after stroke, improves motor function and induces brain plasticity in patients suffering from neurological injury (Taub et al., 1999; Liepert et al., 2000). Our current findings show that implementation of motor training may benefit patients with Parkinson's disease in as profound a manner as that seen in stroke patients. During the degenerative process, motor weakness and fatigue are common and, in view of the present study, may contribute to the loss of nigrostriatal DA neurons. On the other hand, physical training aimed at enhancing the use of affected motor systems may be a beneficial adjunct to current and future therapies.

\section{REFERENCES}

Bilowit DS (1956) Establishing physical objectives in rehabilitation of patients with Parkinson's disease (gymnasium activities). Phys Ther Rev 36:176-178.

Birkmayer W, Riederer P (1975) Responsibility of extrastriatal areas for the appearance of psychotic symptoms (clinical and biochemical human post-mortem findings). J Neural Transm 37:175-182.

Bland ST, Gonzales RA, Schallert T (1999) Movement-related glutamate levels in rat hippocampus, striatum, and sensorimotor cortex. Neurosci Lett 277:119-122.

Bland ST, Schallert T, Strong R, Aronowski J, Grotta JC, Feeney DM (2000) Early exclusive use of the affected forelimb after moderate 
transient focal ischemia in rats: functional and anatomic outcome. Stroke 31:1144-1152.

Bortz II W M, Angwin P, Mefford IN, Boarder MR, Noyce N, Barchas JD (1981) Catecholamines, dopamine, and endorphin levels during extreme exercise. N Engl J Med 305:466-467.

Buonamici M, Cervini MA, Rossi AC, Sebastiani L, Raffaelli A, Bagnoli P (1990) Injections of 6-hydroxydopamine in the substantia nigra of the rat brain: morphological and biochemical effects. Behav Brain Res 38:83-95.

Bury SD, Eichorn AC, Kotzer CM, Jones TA (2000) Reactive astrocytic responses to denervation in the motor cortex of adult rats are sensitive to manipulations of behavioral experience. Neuropharmacology 39:743-755.

Callahan BT, Ricaurte GA (2000) Effect of 7-nitroindazole on body temperature and methamphetamine-induced dopamine toxicity. NeuroReport 9:2691-2695.

Canals JM, Checa N, Marco S, Akerud P, Michels A, Perez-Navarro E, Tolosa E, Arenas E, Alberch J (2001) Expression of brain-derived neurotrophic factor in cortical neurons is regulated by striatal target area. J Neurosci 21:117-124.

Choi-Lundberg DL, Lin Q, Schallert T, Crippens D, Davidson BL, Chang YN, Chiang YL, Qian J, Bardwaj L, Bohn MC (1998) Behavioral and cellular protection of rat dopaminergic neurons by an adenoviral vector encoding glial cell line-derived neurotrophic factor. Exp Neurol $154: 261-275$.

Colbourne F, Whishaw IQ, Kolb B, Metz GAS (2000) The effect of temperature and anesthesia on the unilateral 6-OHDA model in the rat. Soc Neurosci Abstr 26:280.7.

Connor B, Kozlowski DA, Schallert T, Tillerson J, Davidson BL, Bohn MC (1999) Differential effects of glial cell line-derived neurotrophic factor (GDNF) in the striatum and substantia nigra of the aged parkinsonian rat. Gene Ther 6:1936-1951.

Coq JO, Xerri C (1999) Tactile impoverishment and sensorimotor restriction deteriorate the forepaw cutaneous map in the primary somatosensory cortex of adult rats. Exp Brain Res 129:518-531.

Delaney P, Fermaglich J (1976) Parkinsonism and levodopa: a five-year experience. J Clin Pharmacol 16:652-659.

Dunnett SB, Hernandez TD, Summerfield A, Jones GH, Arbuthnott G (1988) Graft-derived recovery from 6-OHDA lesions: specificity of ventral mesencephalic graft tissues. Exp Brain Res 71:411-424.

Emmi A, Rajabi H, Stewart J (1996) Behavioral and neurochemical recovery from partial 6-hydroxydopamine lesions of the substantia nigra is blocked by daily treatment with glutamate receptor antagonists MK-801 and CPP. J Neurosci 16:5216-5224.

Emmi A, Rajabi H, Stewart J (1997) Behavioral and neurochemical recovery from partial 6-hydroxydopamine lesions of the substantia nigra is blocked by daily treatment with D1/D5, but not D2, dopamine receptor antagonists. J Neurosci 17:3840-3846.

Fearnley JM, Lees AJ (1991) Aging and Parkinson's disease: substantia nigra regional selectivity. Brain 114:2283-2301.

Franklyn S, Kohout LJ, Stern GM, Dunning M (1981) Physiotherapy in Parkinson's disease. In: Research progress in Parkinson's disease (Rose FC, Capiledo R, eds), pp 397-400. Tunbridge Wells, United Kingdom: Pittman.

Freed CR, Yamamoto BK (1985) Regional brain dopamine metabolism: a marker for the speed, direction, and posture of moving animals. Science 229:62-65.

Gage FH (2000) Mammalian neural stem cells. Science 287:1433-1438. Ghika J, Ghika-Schmid F, Fankhauser H, Assal G, Vingerhoets F, Albanese A, Bogousslavsky J, Favre J (1999) Bilateral contemporaneous posteroventral pallidotomy for the treatment of Parkinson's disease: neuropsychological and neurological side effects. Report of four cases and review of the literature. J Neurosurg 91:313-321.

Gomez-Pinilla F, So V, Kesslak JP (1998) Spatial learning and physical activity contribute to the induction of fibroblast growth factor: neural substrates for increased cognition associated with exercise. Neuroscience 85:53-61.

Gould E, Tanapat P (1997) Lesion-induced proliferation of neuronal progenitors in the dentate gyrus of the adult rat. Neuroscience 80:427-436.

Gould E, Beylin A, Tanapat P, Reeves A, Shors TJ (1999a) Learning enhances adult neurogenesis in the hippocampal formation. Nat Neurosci 2:260-265.

Gould E, Reeves AJ, Graziano MS, Gross CG (1999b) Neurogenesis in the neocortex of adult primates. Science 286:548-552.

Hefti F, Melamed E, Sahakian BJ, Wurtman RJ (1980) Circling behavior in rats with partial unilateral nigro-striatal lesions: effect of amphetamine, apomorphine, and DOPA. Pharmacol Biochem Behav 12:185-188.

Hirsch EC (2000) Nigrostriatal system plasticity in Parkinson's disease: effect of dopaminergic denervation and treatment. Ann Neurol 47 [4 Suppl 1]:S115-S120; discussion S120-S121.

Humm JL, Kozlowski DA, James DC, Gotts JE, Schallert T (1998) Use-dependent exacerbation of brain damage occurs during an early post-lesion vulnerable period. Brain Res 783:286-292.
Humm JL, Kozlowski DA, Bland ST, James DC, Schallert T (1999) Use-dependent exaggeration of brain injury: is glutamate involved? Exp Neurol 157:349-358.

Hurwitz A (1989) The benefit of a home exercise regimen for ambulatory Parkinson's disease patients. J Neurosci Nurs 21:180-184.

Ivanco TL, Greenough WT (2000) Physiological consequences of morphologically detectable synaptic plasticity: potential uses for examining recovery following damage. Neuropharmacology 39:765-776.

Jensen PN, Holger JM, Smith DF, Rosenberg R (1995) Acute effect of exercise on human blood platelet serotonin uptake and monoamine oxidase activity. Biol Psychiatry 38:125-127.

Jones TA, Schallert T (1994) Use-dependent growth of pyramidal neurons after neocortical damage. J Neurosci 14:2140-2152.

Kempermann G, Brandon EP, Gage FH (1998a) Environmental stimulation of $129 / \mathrm{SvJ}$ mice causes increased cell proliferation and neurogenesis in the adult dentate gyrus. Curr Biol 8:939-942.

Kempermann G, Kuhn HG, Gage FH (1998b) Experience-induced neurogenesis in the senescent dentate gyrus. J Neurosci 18:3206-3212.

Kilbourn MR, DaSilva JN, Frey KA, Koeppe RA, Kuhl DE (1993) In vivo imaging of vesicular monoamine transporters in human brain using $\left[{ }^{11} \mathrm{C}\right]$ tetrabenazine and positron emission tomography. $\mathrm{J}$ Neurochem 60:2315-2318.

Kilbourn MR, Frey KA, Vander Borght T, Sherman PS (1996) Effects of dopaminergic drug treatments on in vivo radioligand binding to brain vesicular monoamine transporters. Nucl Med Biol 23:467-471.

Kleim JA, Lussnig E, Schwarz ER, Comery TA, Greenough WT (1996) Synaptogenesis and fos expression in the motor cortex of the adult rat after motor skill learning. J Neurosci 16:4529-4535.

Klintsova AY, Greenough WT (1999) Synaptic plasticity in cortical systems. Curr Opin Neurobiol 9:203-208.

Knott M (1957) Report of case of parkinsonism treated with proprioceptive facilitation techniques. Phys Ther Rev 37:229.

Kolb B, Whishaw IQ (1998) Brain plasticity and behavior. Annu Rev Psychol 49:43-64.

Kozlowski DA, Schallert T (1998) Relationship between dendritic pruning and behavioral recovery following sensorimotor cortex lesions. Behav Brain Res 97:89-98.

Kozlowski DA, James DC, Schallert T (1996) Use-dependent exaggeration of neuronal injury after unilateral sensorimotor cortex lesions. J Neurosci 16:4776-4786.

Kozlowski DA, Connor B, Tillerson JL, Schallert T, Bohn MC (2000) Delivery of a GDNF gene into the substantia nigra after a progressive 6-OHDA lesion maintains functional nigrostriatal connections. Exp Neurol 166:1-15.

Kuluz JW, Prado R, Chang J, Ginsberg MD, Schleien CL, Busto R (1993) Selective brain cooling increases cortical cerebral blood flow in rats. Am J Physiol 265:H824-H827.

Lapchak PA (1998) A preclinical development strategy designed to optimize the use of glial cell line-derived neurotrophic factor in the treatment of Parkinson's disease. Mov Disord 13 [Suppl 1]:49-54.

Lees AJ (1992) When did Ray Kennedy's Parkinson's disease begin? Mov Disord 7:110-116.

Liepert J, Bauder H, Wolfgang HR, Miltner WH, Taub E, Weiler C (2000) Treatment-induced cortical reorganization after stroke in humans. Stroke 31:1210-1216.

Lindner MD, Plone MA, Francis JM, Blaney TJ, Salamone JD, Emerich DF (1997) Rats with partial striatal dopamine depletions exhibit robust and long-lasting behavioral deficits in a simple fixed-ratio barpressing task. Behav Brain Res 86:25-40.

Lindner MD, Cain CK, Plone MA, Frydel BR, Blaney TJ, Emerich DF, Hoane MR (1999) Incomplete nigrostriatal dopaminergic cell loss and partial reductions in striatal dopamine produce akinesia, rigidity, tremor and cognitive deficits in middle-aged rats. Behav Brain Res 102:1-16.

Luquin MR, Scipioni O, Vaamonde J, Gershanik O, Obeso JA (1992) Levodopa-induced dyskinesias in Parkinson's disease: clinical and pharmacological classification. Mov Disord 7:117-124.

MacRae PG, Spirduso WW, Cartee GD, Farrar RP, Wilcox RE (1997a) Endurance training effects on striatal D2 dopamine receptor binding and striatal dopamine metabolite levels. Neurosci Lett 79:138-144.

MacRae PG, Spirduso WW, Walters TJ, Farrar RP, Wilcox RE (1997b) Endurance training effects on striatal D2 dopamine receptor binding and striatal dopamine metabolites in presenescent older rats. Psychopharmacology 92:236-240.

Mandel RJ, Gage FH, Clevenger DG, Spratt SK, Snyder RO, Leff SE (1999a) Nerve growth factor expressed in the medial septum following in vivo gene delivery using a recombinant adeno-associated viral vector protects cholinergic neurons from fimbria-fornix lesion-induced degeneration. Exp Neurol 155:59-64.

Mandel RJ, Snyder RO, Leff SE (1999b) Recombinant adeno-associated viral vector-mediated glial cell line-derived neurotrophic factor gene transfer protects nigral dopamine neurons after onset of progressive degeneration in a rat model of Parkinson's disease. Exp Neurol 160:205-214.

Miklyaeva EI, Whishaw IQ (1996) Hemiparkinson analogue rats display 
active support in good limbs versus passive support in bad limbs on a skilled reaching task of variable height. Behav Neurosci 110:117-125.

Miklyaeva EI, Castaneda E, Whishaw IQ (1994) Skilled reaching deficits in unilateral dopamine-depleted rats: impairments in movement and posture and compensatory adjustments. J Neurosci 14:7148-7158.

Miklyaeva EI, Martens DJ, Whishaw IO (1995) Impairments and compensatory adjustments in spontaneous movement after unilateral dopamine depletion in rats. Brain Res 681:23-40.

Miller GW, Erickson JD, Perez JT, Penland SN, Mash DC, Rye DB, Levey AI (1999a) Immunochemical analysis of vesicular monoamine transporter (VMAT2) protein in Parkinson's disease. Exp Neurol 156:138-148.

Miller GW, Gainetdinov RR, Levey AI, Caron MG (1999b) Dopamine transporters and neuronal injury. Trends Pharmacol Sci 20:424-429.

Morgan S, Huston JP, Pritzel M (1983) Effects of reducing sensorymotor feedback on the appearance of crossed nigro-thalamic projections and recovery from turning induced by unilateral substantia nigra lesions. Brain Res Bull 11:721-727.

Neeper SA, Gomez-Pinilla F, Choi J, Cotman C (1995) Exercise and brain neurotrophins Nature 373:109.

Neve KA, Kozlowski MR, Marshall JF (1982) Plasticity of neostriatal dopamine receptors after nigrostriatal injury: relationship to recovery of sensorimotor functions and behavioral supersensitivity. Brain Res 244:33-44.

Olanow CW, Tatton WG (1999) Etiology and pathogenesis of Parkinson's disease. Annu Rev Neurosci 22:123-144.

Olsson M, Nikkhah G, Bentlage C, Bjorklund A (1995) Forelimb akinesia in the rat Parkinson model: differential effects of dopamine agonists and nigral transplants as assessed by a new stepping test. J Neurosci 15:3863-3875.

Palmer SS, Mortimer JA, Webster DD, Bistevins R, Dickinson GL (1986) Exercise therapy for Parkinson's disease. Arch Phys Med Rehabil 67:741-745.

Risedal A, Zeng J, Johansson BB (1999) Early training may exacerbate brain damage after focal brain ischemia in the rat. J Cereb Blood Flow Metab 19:997-1003.

Robinson TE, Becker JB (1983) The rotational behavior model: asymmetry in the effects of unilateral 6-OHDA lesions of the substantia nigra in rats. Brain Res 264:127-131.

Robinson TE, Whishaw IQ (1988) Normalization of extracellular dopamine in striatum following recovery from a partial unilateral 6-OHDA lesion of the substantia nigra: a microdialysis study in freely moving rats. Brain Res 450:209-224.

Rosenblad C, Martinez-Serrano A, Bjorklund A (1996) Glial cell linederived neurotrophic factor increases survival, growth and function of intrastriatal fetal nigral dopaminergic grafts. Neuroscience 75:979-985.

Rosenblad C, Martinez-Serrano A, Bjorklund A (1998) Intrastriatal glial cell line-derived neurotrophic factor promotes sprouting of spared nigrostriatal dopaminergic afferents and induces recovery of function in a rat model of Parkinson's disease. Neuroscience 82:129-137.

Rosenblad C, Kirik D, Devaux B, Moffat B, Phillips HS, Bjorklund A (1999) Protection and regeneration of nigral dopaminergic neurons by neurturin or GDNF in a partial lesion model of Parkinson's disease after administration into the striatum or the lateral ventricle. Eur J Neurosci 11:1554-1566.

Sasco AJ, Paffenbarger Jr RS, Gendre I, Wing AL (1992) The role of physical exercise in the occurrence of Parkinson's disease. Arch Neurol 49:360-365.

Schallert T (1988) Aging-dependent emergence of sensorimotor dysfunction in rats recovered from dopamine depletion sustained early in life. Ann NY Acad Sci 515:108-120.

Schallert T, Hall S (1988) "Disengage" sensorimotor deficit following apparent recovery from unilateral dopamine depletion. Behav Brain Res 30:15-24.

Schallert T, Tillerson J (1999) Intervention strategies for degeneration of dopamine neurons in Parkinsonism: optimizing behavioral assessment of outcome. In: Central nervous system diseases (Emerich DF, Dean III RL, Sanberg PR, eds), pp 131-151. Totowa, NJ: Humana.

Schallert T, Wilcox RE (1985) Neurotransmitter-selective brain lesions. In: Neuromethods, Series 1, Neurochemistry, General neurochemical techniques (Boulton AA, Baker GB, eds), pp 343-387. Clifton, NJ: Humana.

Schallert T, Whishaw IQ, De Ryck M, Teitelbaum P (1978) The postures of catecholamine-depletion catalepsy: their possible adaptive value in thermoregulation. Physiol Behav 21:817-820.

Schallert T, Jones T, Weaver M, Shapiro L, Crippens D, Fulton R (1992) Pharmacologic and anatomic considerations in recovery of function. In: Neuropsychological assessment-physical medicine and rehabilitation: state of the art reviews, Vol 6 (Hanson S, Tucker DM, eds), pp 375-393. Philadelphia: Hanley and Belfus Inc.

Schallert T, Kozlowski DA, Humm JL, Cocke RR (1997) Usedependent structural events in recovery of function. Adv Neurol 73:229-238.

Schallert T, Bland ST, Leasure JL, Tillerson JL, Gonzales RA, Williams L, Aronowski J, Grotta J (2000a) Motor rehabilitation, use-related neural events, and reorganization of the brain after injury. In: Cerebral reorganization of function after brain injury (Levin HS, Grafman J, eds), pp 146-167. Oxford: Oxford UP.

Schallert T, Fleming SM, Leasure JL, Tillerson JL, Bland ST (2000b) CNS plasticity and assessment of forelimb sensorimotor outcome in unilateral rat models of stroke, cortical ablation, parkinsonism and spinal cord injury. Neuropharmacology 39:777-787.

Schallert T, Leasure JL, Kolb B (2000c) Experience-associated structural events, subependymal cellular proliferative activity, and functional recovery after injury to the central nervous system. J Cereb Blood Flow Metab 20:1513-1528.

Schultz W (1982) Depletion of dopamine in the striatum as an experimental model of Parkinsonism: direct effects, adaptive mechanisms. Prog Neurobiol 18:121-166.

Schwarting RK, Huston JP (1996) The unilateral 6-hydroxydopamine lesion model in behavioral brain research. Analysis of functional deficits, recovery, and treatments. Prog Neurobiol 50:275-331.

Swinnen SP, Steyver M, Van Den Bergh L, Stelmach GE (2000) Motor learning and Parkinson's disease: refinement of within-limb and between-limb coordination as a result of practice. Behav Brain Res 111:45-59.

Szekely BC, Kosanovich NN, Sheppard W (1982) Adjunctive treatment in Parkinson's disease: physical therapy and comprehensive group therapy. Rehabil Lit 43:72-76.

Taub E, Uswatte G, Pidikiti R (1999) Constraint-induced movement therapy: a new family of techniques with broad application to physical rehabilitation - a clinical review. J Rehabil Res Dev 36:237-251.

Toole T, Hirsch MA, Forkonk A, Lehman DA, Maitland CG (1999) The effects of a balance and strength training program on equilibrium in parkinsonism: a preliminary study. NeuroRehabilitation 14:1-10.

Ungerstedt U (1971) Postsynaptic supersensitivity after 6-hydroxydopamine induced degeneration of the nigro-striatal dopamine system. Acta Physiol Scand Suppl 367:69-93.

van Praag H, Christie BR, Sejnowski TJ, Gage FH (1999) Running enhances neurogenesis, learning, and long-term potentiation in mice. Proc Natl Acad Sci USA 96:13427-13431.

Whishaw IQ (2000) Loss of the innate cortical engram for action patterns used in skilled reaching and the development of behavioral compensation following motor cortex lesions in the rat. Neuropharmacology 39:788-805.

Zigmond MJ (1997) Do compensatory processes underlie the preclinical phase of neurodegenerative disease? Insights from an animal model of parkinsonism. Neurobiol Dis 4:247-253.

Zigmond MJ, Stricker EM (1984) Parkinson's disease: studies with an animal model. Life Sci 35:5-18.

Zigmond MJ, Stricker EM (1989) Animal models of parkinsonism using selective neurotoxins: clinical and basic implications. Int Rev Neurobiol 31:1-79. 